Sādhanā, Vol. 26, Part 4, August 2001, pp. 293-316. (C) Printed in India

\title{
Application of optimisation techniques in groundwater quantity and quality management
}

\author{
AMLAN DAS $^{1}$ and BITHIN DATTA ${ }^{2}$ \\ ${ }^{1}$ Civil Engineering Department, Regional Engineering College, Durgapur \\ 713 209, India \\ ${ }^{2}$ Civil Engineering Department, Indian Institute of Technology, Kanpur \\ 208 016, India \\ e-mail: adas_wrpm@yahoo.com; bithin@iitk.ac.in
}

MS received 1 March 1999; revised 9 April 2001

\begin{abstract}
This paper presents the state-of-the-art on application of optimisation techniques in groundwater quality and quantity management. In order to solve optimisation-based groundwater management models, researchers have used various mathematical programming techniques such as linear programming (LP), nonlinear programming (NLP), mixed-integer programming (MIP), optimal control theory-based mathematical programming, differential dynamic programming (DDP), stochastic programming (SP), combinatorial optimisation $(\mathrm{CO})$, and multiple objective programming for multipurpose management. Studies reported in the literature on the application of these methods are reviewed in this paper.
\end{abstract}

Keywords. Groundwater quantity \& quality management; embedding technique; response matrix approach; optimisation techniques; simulation model; optimisation model.

\section{Introduction}

The goal of a formal mathematical optimisation-based groundwater management model is to achieve a specified objective in the best possible manner within the various limiting restrictions. The limiting restrictions are derived from managerial considerations and physical behaviour of the system. In order to ensure that the final solution does not violate the physical laws of the system, a model simulating the behaviour and response of the system is incorporated within the management model. Once the optimisation model is formulated, a suitable mathematical programming technique is applied to obtain the solution. This paper discusses the applications of various optimisation techniques for the solution of groundwater quantity and quality management problems.

The combined use of simulation and optimisation techniques have been demonstrated to be powerful and useful methods in determining planning and management strategies for optimal development and operation of groundwater systems. Simulation models can 
answer the question: 'What if'. Groundwater system simulation models can simulate the response of the system to a specified management strategy. However, an optimisation model identifies an optimal management strategy from a set of feasible alternative strategies. In order to ensure that the optimal management strategy is physically acceptable, a simulation model is necessary to simulate the system behaviour. The simulation model basically provides solutions that obey the equations governing the relevant processes in the system. Thus the simulation models check for feasibility of a management strategy. The simulation model can be combined with the management model either by using the governing equations as binding constraints in the optimisation model or by using a response matrix (Gorelick 1983) or an external simulation model.

The simulation model component of the management models is based upon the partial differential equations of groundwater flow and solute transport (Bear 1979). Depending upon the physical processes involved with a management model, either the flow equation or the solute transport equation or both the equations are used for simulation.

Embedding technique and response matrix approach are the two methods generally used to incorporate the simulation model within a management model (Gorelick 1983). In embedding technique, the finite difference or finite element form of the governing groundwater flow and solute transport equations are directly incorporated as part of the constraint set in a formal mathematical programming-based management model. Other physical and managerial constraints on heads, gradients, velocities or pumping/injection rates can be incorporated easily. Some of the unknown groundwater variables, i.e. hydraulic heads, source/sink rates, existing solute concentrations, solute concentrations of the source/sink at each node may become decision variables in the optimisation problem. When large numbers of pumping cells are used and steady state management policies are desired, the embedding technique requires less computer memory and processing time than the response matrix approach (Peralta \& Datta 1990). This conclusion may not be valid for transient cases. For nonlinear systems, the response matrix approach is not applicable and use of embedding technique becomes necessary. However, the time step used in the embedding approach for transient problems may require a larger number of variables and constraints for accuracy of the solution. In the response matrix approach, the time step used may not be an important consideration except from the management view point. In highly nonlinear problems such as those involving density dependent transport models, where the response matrix approach is not strictly applicable, a management model even for a small study area may become dimensionally large. Solving such management models using nonlinear optimisation techniques, therefore, becomes difficult. Computational difficulties in using standard optimisation packages for large scale problems are reported by Elango \& Rouve (1980), Gorelick (1983), Tung \& Koltermann (1985), Yazicigil \& Rasheeduddin (1987).

The response matrix approach (Gorelick 1983) uses an external groundwater simulation model to develop unit responses. The unit response describes the influence of a unit change in an independent decision variable/design variable (such as sink/source rates) at preselected well locations, upon a variety of dependent variables/other design variables (such as hydraulic head, velocity, solute concentration) at specified observation points. The assembled unit responses are used to construct the response matrix, which is included in the management model. In order to generate the unit response matrix, a simulation model is solved several times each with a unit stress (pumping/recharge) or concentration loads at a single node. The response matrix approach works on the principles of superposition. It is applicable when the system is linear or approximately linear and the boundary conditions are homogeneous. For highly nonlinear systems, the performance of response matrix 
approach is reported to be unsatisfactory (Rosenwald \& Green 1974). Any change in boundary condition, location of the source/sink, and observation wells requires several simulations to generate the responses and also requires recalculation of the response matrix.

Many researchers have reported the use of embedding technique and/or response matrix approach in conjunction with mathematical programming methods to find a solution of the groundwater management model. The following discussion focuses on the application of different mathematical programming techniques in groundwater management.

\section{Application of linear programming}

Linear programming (LP) techniques can be utilised for solving groundwater quantity and quality management problems when the imposed physical and managerial constraints and the objective function are linear. The capability of LP techniques to solve large-scale problems and to guarantee global optimal solutions has attracted the widespread attention of many researchers in the groundwater management field. Some of the aquifer management problems formulated and solved by using LP technique are discussed here.

Lee \& Aronofsky (1958) developed a linear programming management model to maximise profits from oil production. They used a response matrix that was developed using an analytical solution of the flow equation. They considered a transient management problem. Williams (1962) extended the work of Lee \& Aronofsky (1958) to the scheduling of drilling operations. Wattenberger (1970) used a transient response matrix to develop a linear programming management model which sought to maximise well production.

Deninger (1970) presented a linear programming formulation to maximise water production from a well field. He used the nonequilibrium formula of Theis (1935) to obtain the response matrix.

Aguado \& Remson (1974) introduced linear programming (LP) based management models embedding the finite difference approximation of the governing differential equations as constraints in the formulation. They obtained solutions for example cases of confined and unconfined aquifers, one- and two-dimensional flow fields, and steady state and transient flow conditions. In these examples, the objective was to maximise hydraulic heads at specified locations. They included as constraints some limits on the sum of production rates, and on the monotonicity of the nondecreasing heads in a specified direction. For a steady state one-dimensional unconfined flow case, the nonlinear formulation was converted to a linear formulation by taking the square of hydraulic heads as a linear variable. For a transient one-dimensional confined flow case the partial differential equations were approximated using the Crank-Nicolson scheme. Finite difference equations were written for all nodes for all time periods and then a single LP was solved to obtain the solution over time and space. The transient one-dimensional unconfined flow case is nonlinear. They used the predictor-corrector method of Douglas \& Jones (1963) to approximate the nonlinear partial differential equation by a succession of system of linear difference equation. The predictor step did not result in an LP problem because, the number of equations are equal to the number of variables. It was tridiagonal and could be solved by using the Thomas algorithm. The corrector step resulted in an LP problem. The results of the corrector step were used for the predictor, and the results from the predictor were used for the corrector. Here management could be possible only for one time step.

Aguado et al (1974) applied the LP formulation for dewatering of a large dry dock excavation to predict optimum number of wells, their locations, and rates of pumping needed to maintain ground water levels below specified elevations in a steady state. The 
objective was to minimise total pumping while maintaining steady state groundwater heads below some assigned value in the excavation area.

Remson et al (1974) verified the results obtained from the LP management models against those obtained by using numerical and electrical analog ground-water models.

Morel-Seytoux (1975a,b) developed conjunctive surface water groundwater management models which were solved using linear programming. He used the discrete kernel generator (Morel-Seytoux \& Daly 1975) to develop the response matrix.

Alley et al (1976) applied LP formulation to two-dimensional transient situations in a confined heterogeneous anisotropic aquifer. In the governing differential equation, the source/sink term was expressed as the sum of specified net source/sink and unknown source/sink terms. Their objective was to maximise the hydraulic heads for a portion of the management period such that a fixed total pumping was maintained with a certain minimum pumping from a specified location, while maintaining a certain minimum head during the specified period. For the remaining portion of the management period the objective was to maximise the pumping subject to maintaining of some lower limits for the heads at the interior nodes, with restrictions on pumping at some fixed nodes. This was a different objective and thus could not be formulated as a single problem with the previous one, though these two objectives were applicable to constituent parts in the total management period. The management period was divided into small periods of intervals and solved for each of these small periods separately by using LP. The solution from the previous LP formulation was used as initial condition for the next period. Further they extended the methodology for steady state cases to study the feasibility of disposing of waste water by injection into an aquifer system. The objective was to minimise total pumping from two lines of wells subject to: (i) a reversal of hydraulic gradient towards the pumping well, (ii) maintenance of monotonicity of head values to prevent the recharged waste product from reaching a particular area, and (iii) to meet certain water demands for irrigation.

Futagami et al (1976) presented a method to couple the finite element technique with linear programming for water pollution control. Here the objective was to maximise the pollutant issued from a waste outfall. Constraints of the model were the finite element form of the diffusion convection equation of pollutant movement and water quality requirements.

Molz \& Bell (1977) used a procedure based on linear programming for the initial design of a well field that would create a zero gradient or a finite gradient in a given region. The objective was to maximise total pumping, while satisfying finite difference discretised flow equations for steady state conditions and specified head gradients.

Elango \& Rouve (1980) reported the performance of a finite element based linear programming model. Their study was limited to confined aquifers under steady state conditions. They presented two cases of problems. The first case related to efficient depressurisation of an aquifer. The aquifer considered in this problem was circular in shape in the plan view. The objective was to minimise pumping subject to flow equations, levels of depressurisations at various points, upper limits on pumping capacities and nonnegativity requirements. The flow constraints (equations) were obtained from (a) closed form solutions, and (b) finite element discretised equations. Their result showed the variability in the optimal solutions due to the differences in the chosen finite element configurations. Their second problem related to the maximisation of safe yield of the aquifer. They considered heterogeneity with respect to hydraulic conductivity. The constraints in this problem were finite element flow equations, restrictions on the piezometric heads throughout the aquifer, and nonnegativity conditions. 
Gorelick \& Remson (1982) incorporated the steady state finite difference form of solute transport equation as embedded constraints. They maximised waste disposal at two locations while protecting water quality at supply wells and maintaining an existing waste disposal facility. Postoptimality sensitivity analysis was performed using parametric programming. The objective of the second problem was to identify all sites suitable for waste disposal. They manipulated the linear programming management model so that the optimal value of the dual variable represented unit source impact indicators. It was possible to identify all feasible disposal sites by interpreting the solutions of two linear programming problems.

Gorelick (1982) presented a linear programming based model for maximising waste disposal at several facilities during several one-year planning periods. He used the response matrix approach. The concentration response matrix was obtained by using US Geological Survey method of characteristics, solute transport model (Konikow \& Bredehoeft 1978). The management model was applied to a hypothetical complex groundwater system. These large-field-scale management models were formulated as dual linear programming problems which reduced the numerical difficulties and computation time for solution. The linear programming problems were also solved using MINOS (Murtagh \& Saunders 1993) and MPS/III (Keltron Inc. 1979). The solution results indicated that waste disposal was enhanced by pulsing rather than maintaining constant disposal rates at various sites. Parametric linear programming was used for postoptimality sensitivity analysis.

Heidari (1982) used linear programming in conjunction with response matrix approach for groundwater hydraulic management in the Pawnee Valley of south-central Kansas. He used MINOS to solve the linear programming problems.

Willis (1983) used linear programming to determine the optimal pumping scheme for three consecutive periods in order to meet agricultural water demands. The objectives were to maximise the sum of hydraulic heads and minimise the total deficit. The aquifer considered was unconfined, situated in the Yun Lin basin in Taiwan. The flow equation was quasilinearised using Taylor series expansion. This resulted in a linear approximation which was solved using a iterative procedure. He used the response matrix approach.

Atwood \& Gorelick (1985) presented a linear programming based design methodology for hydraulic gradient control aimed at containing and removing groundwater contaminants. They used the response matrix approach. Their design procedure used a two-stage procedure. In the first stage, solute transport simulation was used to predict the location of the shrinking plume boundary over time, assuming that the regional hydraulic gradient had been effectively flattened in the vicinity of the contaminant plume. The second stage determined the optimal well selection and pumping/recharge schedules by using the simulation-management model. Finally, a simulation model was used to verify the results. Ahlfeld \& Heidari (1994) presented an informative review of linear programming formulations for hydraulic control problems.

For optimal management of a coastal aquifer in southern Turkey, Hallaji \& Yazicigil (1996) used LP technique. They proposed six LP models for steady state and transient state, and one quadratic optimisation model for steady state management of the aquifer system. The general constraints were (i) water demand constraints, (ii) drawdown limitations, (iii) maximum pumping rate constraints, and (iv) minimum pumping rate constraints. The response matrix approach was used to obtain the drawdown limitations. However, the hydraulics of saltwater intrusion was not considered in the response matrix. The objectives considered for the steady state management were (i) maximisation of steady state water withdrawals from the existing wells, (ii) maximisation of withdrawals without any maximum limit on withdrawals from the wells, (iii) minimisation of the sum of 
drawdowns at pumping wells and saltwater-control nodes, and (iv) minimisation of the sum of the drawdowns at the saltwater-control nodes along the coast. The objectives for transient state management were (i) maximisation of the sum of monthly withdrawals, and (ii) minimisation of the sum of drawdowns at the pumping wells and saltwater-control nodes for all pumping periods.

\section{Application of mixed-integer programming}

Mixed-integer programming (MIP) can be used to solve optimisation problems with linear objective function and linear constraints in which some of the variables can take only integer values. These types of requirements arise when dealing with groundwater management problems in which decision variables seek answers of the type yes or no, or the decision variables decide the number of installations, locations etc. In special cases all the variable may take only integer values, where the problem reduces to one of integer programming. Some example applications of MIP in groundwater management are presented in Rosenwald \& Green (1974), Willis (1976), Aguado \& Remson (1980). Galeati \& Gambolati (1988), Ratzlaff et al (1992), and Misirli \& Yazicigil (1997). MIP has also been applied successfully in developing optimal monitoring network for groundwater quality by Meyer \& Brill (1988), Datta \& Dhiman (1995), Loaiciga et al (1992). Some of these applications of MIP for general management of groundwater quality and quantity are presented here.

Rosenwald \& Green (1974) developed a methodology to find the best locations for a specified number of wells. They used the branch and bound method to solve the mixed-integer programming problem and utilised a transient response matrix.

Willis (1976) presented a planning model for the optimal conjunctive use of groundwater and surface water resources. As the pumping, recharges and boundary conditions were known a priori, the flow equations did not need to appear in the constraints. However, the flow equations needed to be solved externally to supply the velocities as fixed coefficients in the transport equation. The steady state solute transport simulation model was first formulated as a finite difference coefficient matrix. The inverse of this matrix was then computed and relevant portions were then included in the management model as constraints. The management model optimised the assimilative waste capacity of the aquifer in waste water treatment. The sum of annual cost of removal and the cost of incorporation of dilution water for all constituents were minimised. The conjunctive use model minimised the costs associated with (i) surface waste water treatment, (ii) dilution water, and (iii) waste water treatment plant. The model considered several unit processes for the waste treatment plant that involved primary, secondary, and various forms of advanced waste treatment. The solution determined the optimal unit treatment process and the most cost effective volume of imported dilution water. The resultant mixed integer programming problem was solved readily by decomposing the overall problem into individual subproblems involving decisions on the amount of dilution water and each unit process combination. Each subproblem minimised a concave objective function subject to a convex linear constraint set.

Aguado \& Remson (1980) (also see the discussions by Elango (1981) and Padmanabhan (1981) as well as the reply by Evans \& Remson (1982)) incorporated the pumping cost and installation costs in the aquifer dewatering problem by reformulating the problem as a fixed-charge problem. The fixed-charge problem was solved using a mixed-integer linear programming algorithm. They used the embedding method and their model was 
applied to an unconfined aquifer. The objective was to minimise the sum of fixed costs due to well installation, and variable costs due to steady state pumping.

Galeati \& Gambolati (1988) used mixed-integer programming to determine an optimal dewatering scheme in the foundation design of an electronuclear plant. They used the response matrix approach. The response matrix was generated using a three-dimensional finite element model for steady state flow conditions.

Ratzlaff et al (1992) used mixed-integer programming for a two-dimensional flow field to determine the best well locations and pumping rates in order to achieve advective containment of contaminant plumes. They used a finite element procedure to generate the response matrix for piezometric head and velocities. Their methodology utilised the idea of delineating the capture zone by imposing segmental implicit velocity direction constraints. Misirli \& Yazicigil (1997) demonstrated the usefulness of the mixed integer programming in groundwater remediation system designs that require installation of interception wells.

\section{Application of nonlinear programming}

Many groundwater planning and management models involve nonlinearities in the objective function and constraints. These nonlinearities may arise due to various causes such as (i) nonlinear cost functions, (ii) nonlinear equations governing the flow particularly for unconfined aquifers, (iii) nonlinearities in the governing equations for solute transport in groundwater, (iv) other types of nonlinear physical and managerial objective functions and constraints. These nonlinear management problems can be solved using nonlinear programming (NLP) algorithms.

Maddock (1972a) used quadratic programming to minimise the present value of pumping costs. He used an algebraic technological function. These technological functions or response coefficients represented the changes in drawdown induced by unit pumping at each well.

Maddock (1972b) used quadratic programming with nonlinear objective function and linear constraints for managing an unconfined aquifer. He developed a nonlinear technological function for the unconfined aquifer which was used in the management model. He used mixed-integer quadratic programming to minimise the pumping costs plus fixed costs for well and pipeline construction. The quadratic portion of the objective function was made separable by a suitable transformation that facilitates the solution by a combination of mixed-integer and separable programming. Further, postoptimality sensitivity and error analysis was performed to evaluate the effects of uncertainties in economic and hydrologic factors, on the planning activities.

Gorelick et al (1984) presented a general modelling approach to determine the optimal design of reclamation schemes for contaminated groundwater systems. The planning model combined a nonlinear, distributed parameter groundwater flow and solute transport simulation model (SUTRA) with a nonlinear optimisation method (MINOS). They used the embedding technique. The planning model was applied for two systems. The first system involved steady-state aquifer reclamation. Contaminant withdrawal, in-ground dilution, and combined pumping/recharge strategies were considered. The second system involved transient flow and transport. Capturing a migrating contaminant plume and in situ dilution were the two management strategies considered.

Colarullo et al (1984) presented a model for hydraulic management and plume stabilisation of a partially contaminated aquifer used for both water supply and waste disposal. They used a quadratic objective function to enhance the economic analysis of a design 
plume by adding constraints on groundwater velocities. They used the response matrix approach.

Lefkoff \& Gorelick (1986) used quadratic programming for design and cost analysis of rapid aquifer restoration systems. They assumed advective groundwater flow and incorporated retardation of solutes due to sorption. The response matrix method was used to simulate the aquifer response in the optimisation model.

Karatzas \& Pinder (1993) incorporated the exponential form of fixed charges (installation cost) into the objective function and solved the problem as a concave minimisation problem. They applied the outer approximation method to concave global minimisation problem over a convex compact set of constraints. They used the response matrix approach and, later, they extended the methodology to nonconvex constraint cases also.

Wang \& Ahlfeld (1994) used MINOS for optimal groundwater remediation planning with well location as a decision variable. For optimal management of a coastal aquifer in southern Turkey, Hallaji \& Yazicigil (1996) used the MINOS algorithm. Their quadratic objective was minimisation of the total pumping costs. Peralta et al (1995a, b), Gharbi \& Peralta (1994) and Takahashi \& Peralta (1995) also used the MINOS algorithm to solve groundwater management problems. In order to solve optimal groundwater remediation design problems, Xiang et al (1994) used NPSOL.

Integrated management of groundwater pollution and withdrawal by using nonlinear optimisation models with embedded simulation constraints was presented by Keshari \& Datta (1996). Two different pattern search methods of nonlinear optimisation, i.e., the Hook and Jeeves, and Powel's conjugate direction method (Reklaitis et al 1983) were utilised. The exterior penalty function approach is also incorporated to avoid the specification of initial feasible solutions.

Some investigators have described some of the proposed groundwater management models as optimal control problems. They classified the system variables as control variables and state variables. In optimal control problem formulations, the control variables govern the evolution of the system from one stage to the next and the state variables describe the behaviour of the system at any stage. The optimal control problems involve a number of stages where each stage evolves from the previous stage in a prescribed manner. The problem is to find a set of control or design variables such that the total objective function, i.e. performance index over the total number of stages, is minimised subject to certain constraints on the state and control variables.

In optimal control problems, the response equations constitute the core of the problem. The response equations explicitly show the dependence of the state variables on the possible planning design or operational decisions. In groundwater planning and management applications, the response equations are obtained by transformation of the system's governing partial differential equations using either the finite element technique or the finite difference technique. The optimal control problem formulations allow the possibilities of joint parameter identification and management, and simultaneous state variable prediction and resource management.

Willis \& Newman (1977) formulated a dynamic management model as a problem in optimal control. The problem was solved by using the mathematical programming technique. The management problem involved minimisation of pumping costs subject to exogenous water demands. The management problem consisted of a nonlinear concave objective function and linear, convex constraints. The solution algorithm of Tui (1964) was used to solve the optimisation problem. This algorithm linearised the objective function with Taylor series expansion about an initial feasible decision vector, and solved linear subproblems to obtain a new basis. 
Willis \& Finney (1985) solved the transient management problem for an unconfined or nonlinear groundwater system directly, by using quasilinearisation and optimal control theory. The management model involved the identification of optimal pumping pattern necessary to satisfy an exogenous water demand. The resulting nonlinear, nonconvex, optimisation problem was solved by using (i) a quasilinearisation based optimisation algorithm, and (ii) the projected augmented Lagrangian method (MINOS). They reported identical optimal solutions using both methods of optimisation.

Wanakule et al (1986) viewed the overall optimal planning and management problem as one of discrete time optimal control. The simulation constraints were conceptually eliminated by expressing the head as an implicit function of pumpage. The resulting reduced problem involved only pumping variables. They solved the overall optimisation problem by using a generalised reduced gradient algorithm of nonlinear programming. The gradients needed for the optimisation were obtained by solving a set of implicit linear difference equations. The hydraulic responses were handled by the response matrix or algebraic technological function method.

Casola et al (1986) solved the management problem for optimal spatial and temporal groundwater allocation for agricultural use. The management model was formulated as a quadratic optimal control problem. The management model maximised the net benefits achieved by supply of water subject to irrigation demands. The mathematical optimisation problem was solved by using MINOS.

Willis \& Finney (1988) presented the planning and management model for the control of seawater intrusion in the Yun Lin regional groundwater basin. The aquifer was unconfined. The management model was formulated as a problem in optimal control. The optimal control problem was solved using (i) the influence coefficient method and quadratic programming, and (ii) the reduced gradient methods in conjunction with a quasi-Newton algorithm (MINOS). The simulation model developed by Mercer et al (1980a, b) was used to simulate the response of the aquifer system within the planning model. The simulation model was based on the assumptions that a sharp interface separates freshwater from seawater. Also, Dupuit's approximations were assumed to be valid. The control variables of the optimisation model were the locations and magnitude of groundwater pumping/recharge. The state variables of the aquifer system were the freshwater head, saltwater head and the location of the interface toe, at the end of the planning period. The objective function minimised a weighted cost function of saltwater intrusion, water supply and recharge volume.

Finney et al (1992) presented the development and application of a quasi three-dimensional optimal control model for groundwater management in the Jakarta coastal aquifer basin. The movement of the freshwater-seawater interface was again based on the sharp interface assumption. The finite difference simulation model of Essaid (1990) was used to simulate the aquifer system response within the control model. The objective function of the model was a function of freshwater and seawater heads, and locations and magnitudes of groundwater pumping, or artificial recharge. The management problem was mathematically a nonlinear nonconvex programming problem with a flat response surface. They reported that MINOS was unable to differentiate between stationary points and local solutions and thus terminated with unusually large reduced gradients. Box's algorithm which is a sequential search algorithm, improved the solution generated by MINOS by approximately $20 \%$.

Das \& Datta (1999a, 1999b, 2000), in a series of three papers, demonstrated the application of the nonlinear programming technique to solve the highly nonlinear problem of seawater intrusion management in coastal aquifers. They considered the density-dependent miscible 
transport case of seawater intrusion in coastal aquifers. They used the embedding technique to incorporate the finite-difference-approximated simulation model within the optimisation model. Multiple objectives for transient and sustainable management were considered in their study.

\section{Application of diferential dynamic programming}

Dynamic programming (DP) techniques are used to solve multistage decision problems. In the dynamic programming technique a multistage decision problem is decomposed into a sequence of single-stage decision problems. Individual single-stage problems may be solved by any method of optimisation. The advantage of using the dynamic programming technique is that it can deal with discrete variables, nonconvex, noncontinuous and nondifferentiable functions. It can also take into account stochastic variability by a simple modification of the deterministic procedure. It requires the separability and monotonicity of the objective function. Dynamic programming suffers from a major drawback known as the curse of dimensionality. However, differential dynamic programming overcomes the curse of dimensionality (i) because the discretisation of the control and state vector is not required, and (ii) by stage wise decomposition. Differential dynamic programming shows linear growth in computing effort with respect to the number of stages or planning periods and also exhibits quadratic convergence. A detailed review of various DP approaches used in water resources management is given in Yakowitz (1982).

Jones et al (1987) used a differential dynamic programming algorithm to solve the unsteady nonlinear groundwater management problem. They formulated the management problem as an optimal control problem. In the DDP solution algorithm, the transfer function i.e. response equations were obtained using finite difference approximations and linearisations of nonlinear dynamics. The Jacobian matrix was computed by implicit differentiation of the simulation equations. The evaluation of the Jacobian required a solution of simultaneous linear equations. They reported that for the test problems, the solution obtained from DDP algorithms were identical to that obtained by using MINOS.

Makinde-Odusola \& Marino (1989) introduced the feedback method of optimal control for solving the groundwater hydraulic management problem of maintaining a target piezometric surface within a confined aquifer. The feedback method was essentially a dynamic programming approach that solves the control problem by deriving a set of feedback rules from a set of recursive equations. The feedback rules in this case were obtained by using a modified version of SUTRA. Once the feedback rule coefficients were evaluated for all time periods, optimal pumping strategies could be derived using the feedback rule and the initial piezometric head vector in a linear forward recursion. The feedback matrix coefficient was a function of (i) aquifer parameter and geometry, and (ii) pumping/recharge node location. The feedback model was essentially an inverse groundwater simulation model. It required assurance about the numerical integrity of the aquifer simulation model and management preferences. A quadratic objective function together with the flow equation constituted the feedback model. The work of Jones et al (1987) may be referred to as deterministic feedback control.

Culver \& Shoemaker (1992) presented a differential dynamic programming algorithm for time varying optimisation of groundwater remediation in which management periods were different from the simulation periods. The pumping policy did not change within the management periods. Because of the incorporation of the management periods which were less in number compared to the simulation periods, the number of control variables were 
fewer in the optimal control problem. The example problem considered a hypothetical, homogeneous, isotropic two-dimensional confined aquifer without leakage. Transition functions were obtained by using a modified version of ISOQUAD (Pinder 1979), an implicit finite element groundwater flow and transport model. The management model minimised total operating cost of pumping and treatment during a given time period subject to constraints on both the state and control variables. They used the penalty function method to handle the constraints.

Chang et al (1992) presented a penalty function approach to obtain solutions to the constrained optimal control problem with a large number of constraints. They used the differential dynamic programming technique to solve the optimal control problem. A hyperbolic penalty function was used to incorporate the constraints.

Culver \& Shoemaker (1993) developed a methodology to improve the computational efficiency of control theory-based optimisation as applied to time varying pump-and-treat groundwater reclamation design. In this methodology, differential dynamic programming with quasi-Newton approximation was combined with a finite element groundwater quality simulation model to determine optimal time-varying pumping policies for reclamation of a contaminated aquifer. They used the penalty function method of constrained nonlinear optimisation. The augmented cost function included the penalty associated with the violation of the constraints and the original quadratic cost function. They used the Broyden rank one quasi-Newton technique to approximate the second derivatives of the groundwater quality model, which were difficult to calculate directly.

\section{Incorporation of uncertainties in groundwater management}

The causes of uncertainty in groundwater management are (i) lack of perfect knowledge about the aquifer system, (ii) inherent variability of system parameters, flow and transport characteristics, and (iii) other factors such as costs and revenues of the project or engineering design and operation of the system. Many researchers studied the effects of uncertainties in groundwater management.

Burt (1967) included random recharge from a stream in his economic study. Maddock (1974) considered the effect of random demand in his distributed parameter aquifer model for conjunctive use of surface water and groundwater. Flores (1975) presented a lumped stochastic model for managing a stream-aquifer system.

One traditional approach for uncertainty analysis in optimisation models is to carry out postoptimality sensitivity analysis to determine the effect on optimal solution of small changes in model data. Maddock (1974) performed a sensitivity analysis in his groundwater management study and found that the results were more sensitive to uncertainties in economic factors rather than the uncertainties in aquifer parameters.

Aguado et al (1977) performed sensitivity analysis on the optimal solutions of the aquifer dewatering model to determine how variations in parameters and input data affect the optimal solutions. This model minimised pumping while meeting specified head values. Discretised equations for groundwater flow were embedded as constraints in the optimisation model. Both finite difference and finite element methods were used for discretisation. Initially, the model was solved assuming an isotropic, homogeneous aquifer. The next step was to vary the hydraulic conductivities systematically throughout the domain and observe the changes in the minimum total pumping rate as indicated by a series of separate LP solutions. Willis (1979) used parametric methods to study the sensitivity of optimal management strategies to changes in water quality standards. 
Gorelick (1982) also used parametric methods to study the sensitivity of total waste disposal to increases in waste injection at disposal sites. In a study of risk management of groundwater contamination, Kaunas \& Haimes (1985) explored the effects of small changes in dispersivity on the exceedence of maximum permissible contamination levels.

Tung (1986) presented a chance constrained stochastic groundwater management model for confined homogeneous and nonuniform aquifer. Cooper-Jacob equation was used to obtain the unit response function. He assumed random nature of transmissivity and storage coefficient. First-order analysis was used to estimate statistical properties of the response function and drawdown at each control point. The model imposed a restriction on the drawdown at any control point, at the end of a given time period. This drawdown resulting from pumping operation over the entire well field did not exceed a specified value with some reliability. The actual constraints of the model were stochastic unit response functions. The deterministic equivalent of the constraint was a quadratic function of the decision variables and hence quasilinearisation was used. The management model maximised pumping rates for three potential wells over three time periods, such that the resulting drawdown at five control points did not exceed a maximum allowable value with specified reliability. Effects of the model reliability and uncertainty level in aquifer parameters estimates on the results were demonstrated.

The effect of spatial variations in transmissivities on aquifer restoration strategies was the topic of Gorelick (1987). He investigated the influence of spatially correlated transmissivity fields upon optimal design strategies. He developed a robust solution method in which a large number of realisations representing spatial variability were incorporated into a single management model. The model found a single reclamation scheme which was feasible for all sample realisations of the transmissivity field. He used the response matrix methods.

Wagner \& Gorelick (1987) presented a nonlinear optimisation based simulation-regressionmanagement model for groundwater quality management under parameter uncertainty. The objective of the model was to identify the best well location and pumping or recharge rates to effect aquifer remediation, with a degree of reliability. The methodology coupled three components: (i) groundwater flow and solute transport simulation (response matrix) combined with nonlinear least squares regression for simultaneous flow and transport parameter estimation, (ii) first-order first- and second-moment analyses to quantify the effects of parameter uncertainty to the management model, and (iii) nonlinear chance constrained stochastic optimisation combined with flow and transport simulation for optimal decision making. The methodology for steady-state and transient aquifer reclamation design was demonstrated. They showed that remediation requirements can increase significantly due to parameter uncertainty. Simulation was used to validate the assumptions made in the first-order moment analysis.

Wagner \& Gorelick (1989) incorporated the effects of uncertainty due to spatial variability of hydraulic conductivity into a procedure for the optimal design of aquifer remediation strategies. Their management procedure was based on the stochastic approach to groundwater flow and contaminant transport modelling, in which the log-hydraulic conductivity was represented as a random field. Their remediation design procedure had two steps. The first step was solution of the stochastic inverse model. Maximum likelihood and Gaussian conditional mean estimation were used to characterise the random conductivity field based on the hydraulic conductivity and hydraulic head measurements. Based on this statistical characterisation, conditional simulation was used to generate numerous realisations of spatially variable hydraulic conductivity. As a second step, the groundwater quality management model was solved. They presented two management model formulations. 
The multiple realisation management model simultaneously solved the nonlinear simulationoptimisation problem for a sampling of hydraulic conductivity realisations. They showed that reclamation design based on a minimum of 30 conductivity realisations can provide reliable remediation strategies. The second one, termed the Monte Carlo management model, solved the nonlinear simulation optimisation problem individually for a sampling of hydraulic conductivity realisations. These results provided a relationship between pumping and reliability.

Hantush \& Marino (1989) presented a chance constrained management model to maximise the pumping from a stream aquifer system, while maintaining limits on heads in the aquifer and depletion from the stream over time with a specified level of reliability. Their model considered variation in hydraulic conductivity and specific yield due to measurement error, spatial averaging and the inherent stochastic description of the porous media. An analytical approximation was used to link drawdowns and stream depletion rates due to pumping. Chance constraints were formulated analytically. They performed sensitivity analysis to assess the effect of the reliability levels used for the chance constraints.

Andricevic \& Kitanidis (1990) combined a dual control algorithm with an extended Kalman filtering scheme for optimisation of the pumping schedule in aquifer remediation with parameter uncertainty. The dual control recognised the interaction between estimation and control. They formulated the groundwater contaminant transport optimisation model as a discrete time optimal control problem. The multistage optimisation problem minimised the sum of deterministic and stochastic costs of remediation. The deterministic costs depended on the best estimates, and the stochastic costs depended on the parameter uncertainties. The multistage optimal control problem was solved using differential dynamic programming technique. The method was illustrated for a one dimensional confined aquifer system. The flow considered was transient. There were one disposal site, one pumping site, and one observation well.

Andricevic (1990) presented a sequential approach to the real-time management and monitoring program of groundwater hydraulics. The management model was formulated as a discrete time optimal control problem. The optimisation problem was solved using differential dynamic programming technique combined with an extended Kalman filter. The management model minimised a penalty function of two conflicting objectives: satisfying withdrawal demands and maintaining target hydraulic head levels. The algorithm was applied to a two-dimensional confined aquifer management problem. The model focused on the parameter uncertainties arising from initial imperfect knowledge. The hydraulic conductivities were assumed to be lognormally distributed.

Lee \& Kitanidis (1991) extended the work of Andricevic \& Kitanidis (1990) to two dimensions. They solved a management problem with four potential wells and three contaminant constraints. Their study also focused on the uncertainty aspects.

Wagner et al (1992) explicitly incorporated the uncertainty about aquifer hydraulic conductivity in a stochastic optimisation model for groundwater quality management. Their optimisation model minimised the expected total cost of operating the pumping wells plus the recourse cost incurred when containment of contaminant plume was not achieved. Their stochastic programming model with recourse minimised the expected total costs over a number of realisations of outcomes of the random parameters. The model was nonlinear and possibly nonconvex. It was solved by an extension of the finite generation algorithm.

Morgan et al (1993) developed the mixed-integer chance constrained programming method for aquifer remediation design under uncertainty. Their method found a globally 
optimal trade-off curve for a maximum reliability objective and a minimum pumping objective.

Ranjithan et al (1993) presented a neural network based screening tool that screened realisations of hydraulic conductivities to determine the critical realisations, which were used subsequently in an optimisation model. The critical realisations were the few realisations of the random parameters that would most constrain the final design. For example, those realisations that would require high volumes of pumping to contain a contaminant plume were the critical realisations. Once the neural network was trained, a large number of hydraulic conductivity realisations could be screened and considerable computational savings could be realised by using only those pessimistic realisations in stochastic optimisation methods. Their screening approach utilised the pattern classification capability of a neural network and its ability to learn from examples.

The work of Tiedeman \& Gorelick (1993) considered the reliable containment of a vinyl chloride plume in an aquifer located in southwest Michigan. They formulated the problem using stochastic nonlinear programming in which the unconfined groundwater flow system was treated as three-dimensional. They compared selected design strategies and analysed the statistical assumptions that form the basis for the stochastic simulation-management model.

Whiffen \& Shoemaker (1993) developed pumping policies for the pump and treat method of groundwater remediation under uncertainty in aquifer characteristics. Their policies used a weighted feedback rule that adjusted pumping rates for any deviation of the observed values of hydraulic head and pollution concentration from predicted values over time. They used the stochastic differential dynamic programming technique for solving the optimisation problem.

\section{Application of combinatorial search algorithms}

In the category of combinatorial search algorithms, two algorithms, viz. the genetic algorithm (GA) and simulated annealing (SA), have been used for groundwater management. Some recent works report the application of GA and SA for solving groundwater management problems.

The genetic algorithm imitates some of the salient features of natural selection and natural genetics in order to find near-optimal solutions in a search space. The genetic algorithm operates on a population of decision variable sets. Three genetic operations, namely selection, cross over, and mutation, are applied on the initialised population to obtain an optimal solution.

Simulated annealing uses the analogy between (i) the cooling and annealing process of solids, and (ii) optimisation of a multivariable function. However, this is an imperfect analogy. The five major steps of simulated annealing are: (1) representation of the possible system configuration in a concise form, (2) specification of the penalty type objective function, (3) rearrangement of the system, (4) control parameter and annealing schedule and (5) criteria for terminating the algorithm.

More details on genetic algorithm and simulated annealing can be found in Goldberg (1989), Holland (1975), Kirkpatrick et al (1983), Press et al (1986), Van Laarhoven \& Aarts (1987), and Aarts \& Korst (1989).

Ritzel et al (1994) used genetic algorithms to solve a multiple objective groundwater pollution containment problem. They used the response matrix approach. Their objectives were maximisation of reliability and minimisation of costs. The source of uncertainty was 
the hydraulic conductivity which was assumed to be lognormally distributed with a known mean, variance, and correlation length. Steady state flow was considered in a $30 \times 30$ grid of a hypothetical confined aquifer system with known boundary conditions. They used both the vector-evaluated genetic algorithm and the Pareto genetic algorithm. The Pareto genetic algorithm was shown to be capable of incorporating the fixed costs. The trade-off curves generated by the Pareto genetic algorithm were similar to that obtained via mixed-integer chance constrained programming. The Pareto genetic algorithm was shown to be superior to the vector evaluated genetic algorithm.

McKinney \& Lin (1994) also used the genetic algorithm to solve groundwater management problems. Their first example determined maximum yield from a homogeneous isotropic unconfined aquifer. Their second example determined the minimum cost combination of wells to supply an exogenous demand of water from an unconfined aquifer. The third example determined a minimum cost pump-and-treat remediation system design to remove a contaminant plume from a aquifer using air-stripping treatment technology. For this problem they used the response matrix approach.

Dougherty \& Marryott (1991) applied the simulated annealing technique for optimal groundwater management. They illustrated the method using (i) a dewatering problem, (ii) a dewatering problem with zooming, (iii) a contamination problem, and (iv) contaminant removal with slurry walls.

Marryott et al (1993) presented the field-scale application of the simulated annealing method for optimal groundwater remediation at a contaminated field site. Rizzo and Dougherty (1996) extended the SA technique for multiple management period groundwater remediation.

\section{Application of the artificial neural networks technique}

Artificial neural networks (ANN) are intended for modelling the organisational principles of the central nervous system in the hope that the biologically inspired computing capabilities of ANN will allow the cognitive and sensory tasks to be performed more easily and more satisfactorily than with conventional methods. The network architecture has three basic components, namely: (i) a weighted summer which accumulates the weigted sum of the incoming signals to a neuron from other interconnected neurons; (ii) a linear dynamimc system; and a (iii) a nondynamic nonlinear function i.e. the transfer function defining the output responses of a neuron for a given input signal. Formulation of the network is the crux in the ANN technique. Training of the network is the mext phase in the ANN technology. For training of a network in a groundwater system, several groundwater responses corresponding to the aquifer stress scenarios are used. Once an ANN is trained to imitate a particular aquifer system, it can be suitably applied for further use in optimal management of the system also. Rogers \& Dowla (1994) report the use of the ANN technique for optimal groundwater remediation design.

\section{Application of multiple objective mathematical programming}

Groundwater management problems are often formulated as multiple objective mathematical programming problems with many conflicting and noncommensurable objectives. Therefore, a set of Pareto optimal, nondominated, or noninferior (efficient) solutions is generally determined for the multiobjective optimisation problem. This set of noninferior solutions, also known as the Pareto optimal set, is a subset of the feasible set of solutions and it 
contains solutions for which any improvement of one objective function value can be achieved only at the expense of another objective function value. The Pareto optimal solutions are represented by a trade-off curve relating two conflicting objectives. Multiple objective management models generally attempt to develop such trade-off curves.

Willis (1977) used response equations as embedded constraints in a multiple objective optimisation model for groundwater quality management. The conjunctive management model of the regional unconfined aquifer determines the optimal pumping and injection locations and rates, and minimum surface storage capacity compatible with exogenous waste load. The multiple objectives were: (a) maximise the minimum hydraulic head within the pumping region of the groundwater basin, i.e., minimise operational costs of pumping, (b) minimise the minimum head within the injection region of the aquifer i.e. minimise injection, and (c) minimise the surface waste water storage capacity i.e. maximise injection rates. Constraints were the system response equations, water demand and waste load, and storage capacity, upper bounds on pumping, maximum and minimum permissible heads, non-negativity of the state and decision variables. Nonlinear objectives were transformed to linearised form and finally a linear programming problem was formulated and solved. The aquifer was assumed to be homogeneous, anisotropic and divided into four zones. He used the weighting method to find solutions of the multiple objective management model.

Willis (1979) considered the problems associated with injection of waste waters in groundwater aquifer system conjunctively managed for supply and quality. The aquifer system was assumed to be sufficiently well-defined to allow subsurface waste disposal. Optimal policies determined the pumping and injection schedules (rates and locations) necessary to satisfy constraints on exogenous water supply target, waste load demand, and the maximum waste injection concentrations that were compatible with the prevailing groundwater quality standards of the basin. Management of the flow and quality of the groundwater system together is a nonlinear nonconvex programming problem. As mentioned by Willis (1979) the sources of nonconvexity are the solute transport equations of the groundwater system. The nonlinearity was in the objective functions as well as the constraints. Thus to make the problems linear, management problems were decomposed into two interdependent subproblems. Decomposition was based on the assumption that management objectives are separable functions of the decision or policy variables. The first problem used linear programming to determine the optimal pumping and waste injection schedules. These schedules were used in the second problem to determine optimal waste injection concentrations compatible with the environmental quality standard of the system. Response equations were obtained by using the Galerkin finite element method. Constraints were the response equations, water target requirements within any planning period, waste load disposal limits, upper limits on pumping and recharge capabilities, groundwater quality, and nonnegativity. In this model, physical variables were used as surrogate variables for the cost and benefit functions typically associated with groundwater resource management. The system objectives were: (i) maximise the minimum heads for all the pumping wells, (ii) minimise the maximum heads for all the recharge wells, and (iii) maximise the minimum waste injection rates. These nonlinear objectives were transformed into linear objectives by defining additional variables and constraint equations for the model. He used the weighting method in conjunction with linear programming to solve the multiple objective management model.

Shamir et al (1984) addressed the annual operation of a coastal aquifer in the light of multiple objectives and constraints dictated by long-range considerations. The multipleobjective linear programming model was based on a multicell model of the aquifer and 
network representation of the hydraulic distribution system. The four objective functions of their model were based on: (1) desired groundwater surface configuration, (2) a desired location of seawater-freshwater interface toe in each coastal cell, (3) a desired concentration distribution for a selected conservative contaminant, and (4) minimum energy for pumping and recharge. They incorporated the location of the seawater-freshwater interface by using an approximate linearised expression. The constraint method (Cohon \& Marks 1975) of multiple objective analysis was used to obtain trade-off functions between pairs of objectives.

Willis \& Liu (1984) presented the application of an optimisation model to the Yun Lin groundwater basin in southwestern Taiwan. Parametric linear programming was used to generate optimal planning policies and the set of noninferior solutions. The aquifer system considered was heterogeneous and isotropic. The response equations were obtained using the Galerkin finite element method. The objectives were to determine the trade-offs associated with additional groundwater development and agricultural demands. Thus it maximised the sum of the hydraulic heads in the basin, and minimised the total water deficit for the entire basin. The constraints were response equations, well capacities, hydraulic gradients, lower bounds on heads and water demands.

Datta \& Peralta (1986) applied surrogate worth trade-off method of multiple objective programming to conjunctive groundwater and surface water management. They presented a set of interactive, computer graphics-based procedures in relation to surrogate worth trade-off method to select a single strategy from a nondominated set of solutions. The finite difference discretisation of a two-dimensional steady state groundwater flow equation was used. They used the embedding technique with quadratic programming. The two objectives considered were the minimisation of the total cost of water use, and maximisation of total withdrawal from the aquifer.

Yazicigil \& Rasheeduddin (1987) used multiple objective programming techniques to determine the optimal groundwater management schemes in a hypothetical multi-aquifer system. Three-dimensional implicit finite difference approximations of the governing partial differential equations for the groundwater flow similar to that given by McDonald \& Harbaugh (1984) were used to describe the system state equations. They used the embedding technique in conjunction with linear programming to solve the management problems. Both single and multiple objectives were considered The single objective case was applied to the transient case of aquifer management. The multiple objective case considered steady state management. Constraints and weighting methods of the multiple objective programming techniques were used to develop trade-off curves between the sum of hydraulic heads in the whole system and the individual aquifer for various water production targets.

Peralta \& Datta (1990) approached the multiple objective problem by simultaneously changing entire sets of bounds or boundary conditions. This approach is practical when a model uses a large number of bounds or constraints to represent spatially distributed implicit objectives. They used the embedding technique with linear and quadratic programming. The objectives were (i) maximisation of the total withdrawal from the aquifer subject to sustained yield hydraulic constraints, and (ii) maximisation of the sustainable maintenance of a specified spring time potentiometric surface.

Yazicigil (1990) presented multiple objective groundwater management models to determine the optimal planning and operation of a multiaquifer system. He used response matrix approach with linear and quadratic programming techniques. The management problem considered a planning period of eight years with annual pumping periods. Three models were formulated. The first one, a linear programming model, maximised agricultural 
water withdrawals. The second model, a linear programming model, minimised the sum of drawdowns at all well fields for all planning periods. A trade-off curve between total drawdown and total pumping was obtained from this model. The third quadratic programming optimisation model minimised the total discounted pumping costs over the planning horizon. The agricultural utilisation models assumed that the municipal demands were fixed. In order to optimise the municipal water withdrawals in addition to agricultural uses, the second and third models were used to formulate management models for three more scenarios. The scenarios considered were pumping within cells only, pumping from cluster of well fields, and pumping from all well fields.

Bogardi et al (1991) presented an interactive multiobjective decision-making method for analysing groundwater management problems. They used a finite difference groundwater flow model to obtain the response matrix. They applied the model to a hypothetical, homogeneous, isotropic, confined aquifer under steady state conditions. The objectives were: maximisation of total yield, minimisation of maximum compression at 10 preselected wells, and minimisation of total pumping cost. They developed an interactive, one-dimensional search method, called as search beam method, to generate quasi-nondominated solutions. They did not propose any formal optimisation method.

Shafike et al (1992) used three different multicriterion decision-making techniques, viz., compromise programming, Electre III, and MCQA II, to analyse and rank discrete sets of alternatives in groundwater contamination management problem. Response functions of Maddock (1972) were used to describe hydraulic drawdown and velocity in a homogeneous and isotropic confined aquifer. The conflicting objectives considered were maximisation of water supply volume, minimisation of the drawdown in containment wells, and minimisation of total pumping costs. They used the constraint method to generate a discrete set of nondominated solutions.

Duckstein et al (1994) applied four multicriterion decision making techniques for ranking groundwater management alternatives. These techniques were compromise programming, Electre III, multiattribute utility function, and UTA. The objectives were to optimise pumping yield, total costs, and water-shortage risks. They used a finite element method and a combined embedding/response matrix method. They concluded that all four methods were equally promising for use as a decision-aid tool to select appropriate management scheme.

El Magnouni \& Treichel (1994) presented a multiple objective linear programming based approach to groundwater quantity (hydraulic) management. They used finite element and embedding methods. They applied the model to the management of an unconfined aquifer. The nonlinearities resulting from functional dependence of aquifer parameters on hydraulic head were handled iteratively.

\section{Conclusion}

In the last three decades, several groundwater management models have been developed for various applications, such as, domestic and agricultural water supply, aquifer dewatering for excavations, conjunctive use of surface and groundwater for quality and quantity, utilisation of assimilative capacity of the aquifer for waste injection, remediation of a contaminated aquifer, containment and isolation of the contaminant plume in the groundwater, and prevention of seawater intrusion. In order to solve optimisation based groundwater management models, researchers have used various mathematical programming techniques such as linear programming (LP), nonlinear programming (NLP), mixed integer programming 
(MIP), optimal control theory based mathematical programming, differential dynamic programming (DDP), stochastic programming (SP), combinatorial optimisation (CO), and multiple objective programming for multipurpose management (Yeh 1992). State of the art on application of optimisation techniques in groundwater quality and quantity management is presented in this paper.

\section{References}

Aarts E, Korst J 1989 Simulated annealing and boltzmann machines (New York: John Wiley) Aguado E, Remson I 1974 Groundwater hydraulics in aquifer management. J. Hydraul. Div., Am. Soc. Civ. Eng. HY1-100: 103-118

Aguado E, Remson I 1980 Groundwater management with fixed charges. J. Water Resour. Planning Manage. Div., Am. Soc. Civ. Eng. WR2-106: 375-382

Aguado E, Remson I, Pikul M F, Thomas W A 1974 Optimal pumping for aquifer dewatering. J. Hydraul. Div., Am. Soc. Civ. Eng. HY7-100: 860-877

Aguado E, Sitar N, Remson I 1977 Sensitivity analysis in aquifer studies. Water Resour. Res. 13: 733-737

Ahlfeld D P, Heidari M 1994 Applications of optimal hydraulic control to groundwater systems. J. Water Resour. Planning Manage. Div., Am. Soc. Civ. Eng. 120: 350-365

Alley W M, Aguado E, Remson I 1976 Aquifer management under transient and steady-state conditions. Water Resour. Bull. 12: 963-972

Andricevic R 1990 A real-time approach to management and monitoring of groundwater hydraulics. Water Resour. Res. 26: 2747-2755

Andricevic R, Kitanidis P K 1990 Optimisation of the pumping schedule in aquifer remediation under uncertainty. Water Resour. Res. 26: 875-885

Aronofsky J S, Williams A C 1962 The use of linear programming and mathematical models in underground oil production. Manage. Sci. 8: 374-407

Atwood D F, Gorelick S M 1985 Hydraulic gradient control for groundwater contaminant removal. J. Hydrol. 76: 85-106

Bear J 1979 Hydraulics of groundwater (New York: Mc-Graw Hill)

Bogardi J J, Das Gupta A, Jiang H Z 1991 Search beam method, a promising way to define non-dominated solution in multiobjective groundwater development. Int. J. Water Resour. Dev. 7: 247-258

Burt O R 1967 Temporal allocation of groundwater. Water Resour. Res. 3: 45-56

Casola W H, Narayanan R, Duffy C, Bishop A B 1986 Optimal control model for groundwater management. J. Water Resour. Planning Manage., Div. Am. Soc. Civ. Eng. 112: 183-197

Chang L C, Shoemaker C A, Liu P L F 1992 Optimal time-varying pumping rates for groundwater remediation: application of a constrained optimal control algorithm. Water Resour. Res. 28: 3157-3173

Cohon J L, Marks D H 1975 A review and evaluation of multiobjective programming techniques. Water Resour. Res. 11: 208-220

Colarullo S J, Heidari M, Maddock T III 1984 Identification of an optimal groundwater strategy in a contaminated aquifer. Water Resour. Bull. 20: 747-760

Culver T B, Shoemaker C A 1992 Dynamic optimal control for groundwater remediation with flexible management periods. Water Resour. Res. 28: 629-641

Culver T B, Shoemaker C A 1993 Optimal control for groundwater remediation by differential dynamic programming with quasi-Newton approximations. Water Resour. Res. 29: 823-831

Datta B, Dhiman S D 1996 Chance constrained optimal monitoring network design for 
pollutants in groundwater. J. Water Resour. Planning Manage. Div., Am. Soc. Civ. Eng. 122: $180-188$

Datta B, Peralta R C 1986 Interactive computer graphics-based multiobjective decision-making for regional groundwater management. Agric. Water Manage. 11: 91-116

Das A, Datta B 1999a Development of multiobjective management models for coastal aquifers. J. Water Res. Planning Manage., Am. Soc. Civ. Eng. 125: 76-87

Das A, Datta B 1999b Development of management models for sustainable use of coastal aquifers. J. Irrigation Drainage Eng., Am. Soc. Civ. Eng. 125: 112-121

Das A, Datta B 2000 Optimisation based solution of density dependent seawater intrusion in coastal aquifers. J. Hydrol. Eng., Am. Soc. Civ. Eng. 5: 82-89

Deninger R A 1970 Systems analysis of water supply systems. Water Resour. Bull. 6: 573-579

Dougherty D E, Marryott R A 1991 Optimal groundwater management 1. Simulated annealing. Water Resour. Res. 27: 2493-2508

Douglas J Jr, Jones B F 1963 On predictor-corrector methods for nonlinear parabolic differential equations. SIAM J. Appl. Math. : 195-204

Duckstein L, Treichel W, El Magnouni S 1994 Ranking groundwater management alternatives by multicriterion analysis. J. Water Resour. Planning Manage., Div. Am. Soc. Civ. Eng. 120: $546-565$

Elango K, Rouve G 1980 Aquifers: Finite-element linear programming model. J. Hydraul. Div., Am. Soc. Civ. Eng. HY10-106: 1641-1658

Elango K 1981 Discussion of groundwater management with fixed charges by Aguado E and Remson I. J. Water Resour. Planning Manage. Div., Am. Soc. Civ. Eng. 107: 583

Essaid H I 1990 A multilayered sharp interface model of coupled freshwater and saltwater in coastal systems: Model development and application. Water Resour. Res. 27: 1431-1454

El Magnouni S, Treichel W 1994 A multicriterion approach to groundwater management. Water Resour. Res. 30: 1881-1895

Evans B, Remson I 1982 Closure: groundwater management with fixed charges by Aguado E and Remson I. J. Water Resour. Planning Manage. Div., Am. Soc. Civ. Eng. 108: 237

Finney B A, Samsuhadi, Willis R 1992 Quasi-three-dimensional optimisation model for Jakarta basin. J. Water Resour. Planning Manage. Div., Am. Soc. Civ. Eng. 118: 18-31

Flores E Z, Gutjahr A L, Gelhar L W 1975 A stochastic model of the operation of a stream-aquifer system. Water Resour. Res. 14: 30-38

Futagami T, Tamai N, Yatsuzuka M 1976 FEM coupled with LP for water pollution control. J. Hydraul. Div., Am. Soc. Civ. Eng. HY7-102: 881-897

Galeati G, Gambolati G 1988 Optimal dewatering schemes in the foundation design of an electronuclear plant. Water Resour. Res. 24: 541-552

Gharbi A, Peralta R C 1994 Integrated embedding optimisation applied to Salt Lake valley aquifers. Water Resour. Res. 30: 817-832

Goldberg D E 1989 Genetic algorithm in search, optimisation, and machine learning (Reading, MA: Addison-Wesley)

Gorelick S M 1982 A model for managing sources of groundwater pollution. Water Resour. Res. 18: 773-781

Gorelick S M 1983 A review of distributed parameter groundwater management modeling methods. Water Resour. Res. 19: 305-319

Gorelick S M 1987 Sensitivity analysis of optimal groundwater contaminant capture curves: spatial variability and robust solutions. In Proceedings, NWWA Conference Solving Groundwater Problems with Models (Dublin, OH: National Water Well Association) pp 133-146

Gorelick S M, Remson I 1982 Optimal location and management of waste disposal facilities affecting groundwater quality. Water. Resour. Bull. 18: 43-51 
Gorelick S M, Voss C I, Gill P E, Murray W, Saunders M A, Wright M H 1984 Aquifer reclamation design: The use of contaminant transport simulation combined with nonlinear programming. Water Resour. Res. 20: 415-427

Hallaji K, Yazicigil H 1996 Optimal management of a coastal aquifer in southern Turkey. J. Water Res. Planning Manage. Div., Am. Soc. Civ. Eng. 122: 233-244

Hantush M M S, Marino M A 1989 Chance-constrained model for management of a stream-aquifer system. J. Water Resour. Planning Manage. Div., Am. Soc. Civ. Eng. 115: 259-277

Heidari M 1982 Application of linear systems theory and linear programming to groundwater management in Kansas. Water Resour. Bull. 18: 1003-1012

Holland J H 1975 Adaption in natural and artificial systems (Ann Arbor, MI: University of Michigan Press)

Jones L, Willis R, Yeh W W G 1987 Optimal control of nonlinear groundwater hydraulics using differential dynamic programming. Water Resour. Res. 23: 2097-2107

Karatzas G P, Pinder G F 1993 Groundwater management using numerical simulation and the outer approximation method for global optimisation. Water Resour. Res. 29: 3371-3378

Karatzas G P, Pinder G F 1996 The solution of groundwater quality management problems with a nonconvex feasible region using a cutting plane optimisation technique. Water Resour. Res. 32: 1091-1100

Kaunas J R, Haimes Y Y 1985 Risk management of groundwater contamination in a multiobjective framework. Water Resour. Res. 21: 1721-1730

Keltron Inc. 1979 MPS/III, Mathematical programming system, User Manual, Management Sci. System Div., Arlington, Va

Keshari A K, Datta B 1996 Multiobjective management of a contaminated aquifer for agricultural use. Water Resour. Manage. 10: 373-395

Kirkpatrick S, Gelatt C D, Vecchi M P 1983 Optimisation by simulated annealing. Science 220: $671-680$

Konikow L F, Bredehoeft 1978 Computer model of two-dimensional solute transport and dispersion in groundwater. US Geol. Survey Tech. Water Resour. Investigation, Book no. 7

Lee A S, Aronafsky J S 1958 A linear programming model for scheduling crude oil production. J. Petrol Technol. 213: 51-54

Lefkoff L J, Gorelick S M 1986 Design and cost analysis of rapid aquifer restoration systems using flow simulation and quadratic programming. Ground Water 24: 777-790

Loaiciga H A, Charbeneau R J, Everett L G, Fogg G E, Hobbs B F, Rouhani S 1992 Review of groundwater quality monitoring network design. J. Hydraul. Eng. 118: 11-37

Maddock T III 1972a Algebraic technological function from a simulation model. Water Resour. Res. 8: 129-134

Maddock T III 1972b A groundwater planning model: A basis for a data collection network. Presented at the Int. Symp. on Uncertainties in Hydrologic and Water Resource Systems (Tuscon, AZ: Int. Assoc. Sci. Hydrol.)

Maddock T III 1974 The operation of stream-aquifer system under stochastic demands. Water Resour. Res. 10: 1-10

Makinde-Odusola B A, Marino M A 1989 Optimal control of groundwater by the feedback method of control. Water Resour. Res. 25: 1341-1352

Marryott R A, Dougherty D E, Stollar R L 1993 Optimal groundwater management: Application of simulated annealing to a field scale contamination site. Water Resour. Res. 29: 847-860

McDonald M G, Harbaugh A W 1984 A modular three-dimensional finite difference ground-water flow model (Washington, DC: Scientific Publication Co.) 
McKinney D C, Lin M 1994 Genetic algorithm solution of groundwater management models. Water Resour. Res. 30: 1897-1906

Mercer J W, Larson S P, Faust C R 1980 Simulation saltwater interface motion. Ground Water 18: 374-385

Meyer P D, Brill E D 1988 A method for locating wells in a groundwater monitoring network under conditions of uncertainty. Water Resour. Res. 24: 1277-1282

Misirli F, Yazicigil H 1997 Optimal ground-water pollution containment with fixed charges. J. Water Res. Planning Manage. Am. Soc. Civ. Eng. 123: 2-12

Molz F J, Bell L C 1977 Head gradient control in aquifers used for fluid storage. Water Resour. Res. 13: 795-798

Morel-Seytoux H J 1975a A simple case of conjunctive surface-groundwater management. Ground Water 13: 505-515

Morel-Seytoux H J 1975b Optimal legal conjunctive operation of surface and ground waters. Presented at the Second World Congress Int. Water Resour. Assoc. New Delhi

Morel-Seytoux H J, Daly C J 1975 A discrete kernel generator for stream-aquifer studies. Water Resour. Res. 11: 253-260

Morgan D R, Eheart J W, Valocchi A J 1993 Aquifer remediation design under uncertainty using a new chance constrained programming technique. Water Resour. Res. 29: 551-561

Murtagh B A, Saunders M A 1993 MINOS 5.4 user's guide. Technical report, SOL 83-20R, Systems Optimisation Laboratory, Department of Operations Research, Stanford University, Stanford, CA

Padmanabhan G 1981 Discussion of groundwater management with fixed charges by Aguado E and Remson I. J. Water Resour. Planning Manage. Div., Am. Soc. Civ. Eng. 107: 584

Peralta R C, Datta B 1990 Reconnaissance - level alternative optimal groundwater use strategies. J. Water Resour. Planning Manage. Div., Am. Soc. Civ. Eng 116: 676-692

Peralta R C, Cantiller R R, Terry J E 1995 Optimal large-scale conjunctive water-use planning: case study. J. Water Resour. Planning Manage. Div., Am. Soc. Civ. Eng. 121: 471-478

Peralta R C, Solaimanian J, Musharrafich G R 1995b Optimal dispersed groundwater contaminant management: MODCON method. J. Water Resour. Planning Manage. Am. Soc. Civ. Eng. 121: 490-498

Pinder G F 1979 Galerkin finite element models for aquifer simulation. Rep. 76-WR-5, Department of Civil Engineering, Princeton University, Princeton, NJ

Press W H, Flannery B P, Tenkolsky S A, Vetterling W T 1986 Numerical recipes, the art of scientific computing (New York: Cambridge University Press)

Ranjithan S, Eheart J W, Garrett Jr J H 1993 Neural network-based screening for groundwater reclamation under uncertainty. Water Resour. Res. 29: 563-574

Ratzlaff S A, Aral M M, Al-Khayyal F 1992 Optimal design of ground-water capture systems using segmental velocity-direction constraints. Ground Water 30: 6507-612

Reklaitis G V, Ravindran A, Ragsdell K M 1983 Engineering optimisation methods and applications (New York: John Wiley and Sons)

Remson K A, Aguado E, Remson I 1974 Tests of a groundwater optimisation technique. Ground Water 12: 273-276

Ritzel B J, Eheart J W, Ranjithan S 1994 Using genetic algorithms to solve a multiple objective groundwater pollution containment problem. Water Resour. Res. 30: 1589-1603

Rizzo D M, Dougherty D E 1996 Design optimisation for multiple management period groundwater remediation. Water Resour. Res. 32: 2549-2561

Rogers L L, Dowla F U 1994 Optimisation of groundwater remediation using artificial neural networks with parallel solute transport modeling. Water Resour. Res. 30: 457-481 
Rosenwald G W, Green D W 1974 A method for determining the optimum location of wells in a reservoir using mixed-integer programming. Soc. Res. Eng. J. 14: 44-54

Shafike N G, Duckstein L, Maddock T III 1992 Multiobjective analysis of groundwater contamination management. Water Resour. Bull. 28: 33-43

Shamir U, Bear J, Gamliel A 1984 Optimal annual operation of a coastal aquifer. Water Resour. Res. 20: 435-444

Takahashi S, Peralta R C 1995 Optimal perennial yield planning for complex nonlinear aquifers: Methods and examples. Adv. Water Resour. 18: 49-62

Theis C V 1935 The relation between the lowering of the piezometric surface and the rate and duration of discharge of a well using groundwater storage. Trans. Am. Geophys. Union 16: 519-524

Tiedeman G, Gorelick S M 1993 Analysis of uncertainty in optimal groundwater contaminant capture design. Water Resour. 29: 2139-2153

Tui H 1964 Concave programming under linear constraints. Dokl. Akad. Nauk SSSR 159: $32-35$

Tung Y K 1986 Groundwater management by chance-constrained model. J. Water Resour. Planning Manage. Div., Am. Soc. Civ. Eng. 112: 1-19

Tung Y K, Kolterman C E 1985 Some computational experience using embedding technique for groundwater management. Ground Water 23: 455-456

Van Laarhoven P J M, Aarts E H L 1987 Simulated annealing: Theory and applications (Boston, MA: Kluwer Academic)

Wagner B J, Gorelick S M 1987 Optimal groundwater quality management under parameter uncertainty. Water Resour. Res. 23: 1162-1174

Wagner B J, Gorelick S M 1989 Reliable aquifer remediation in the presence of spatially variable hydraulic conductivity: From data to design. Water Resour. Res. 25: 2210-2225

Wagner J M, Shamir U, Nemati H R 1992 Groundwater quality management under uncertainty: Stochastic programming approaches and the value of information. Water Resour. Res. 28: 1233-1246

Wanakule N, Mays L W, Lasdon L S 1986 Optimal management of large-scale aquifers: methodology and applications. Water Resour. Res. 22: 447-465

Wang W, Ahlfeld D P 1994 Optimal groundwater remediation with well location as a decision variable: Model development. Water Resour. Res. 30: 1605-1618

Wattenberger R A 1970 Maximising seasonal withdrawals from gas storage reservoirs. $J$. Petrol Technol:: 994-998

Whiffen G J, Shoemaker C A 1993 Nonlinear weighted feedback control of groundwater remediation under uncertainty. Water Resour. Res. 29: 3277-3289

Willis R 1976 Optimal groundwater quality management: Well injection of waste water. Water Resour. Res. 12: 47-53

Willis R 1977 Optimal groundwater resource management using the response equation method. In Finite elements in water resources (eds) W G Gray, G F Pinder (London: Pentech)

Willis R 1979 A planning model for the management of groundwater quality. Water Resour. Res. 15: $1305-1312$

Willis R 1983 A unified approach to regional groundwater management, in groundwater hydraulics. Water resources monograph series (eds) J S Rosenshein, G D Bennett (Washington, DC: Am. Geophys. Union)

Willis R, Finney B A 1985 Optimal control of nonlinear groundwater hydraulics: theoretical development and numerical experiments. Water Resour. Res. 21: 1476-1482

Willis R, Finney B A 1988 Planning model for optimal control of saltwater intrusion. J. Water Resour. Planning Manage., Div. Am. Soc. Civ. Eng. 114: 163-178 
Willis R, Liu P 1984 Optimisation model for groundwater planning. J. Water Resour. Planning Manage. Div., Am. Soc. Civ. Eng. 110: 333-347

Willis R, Newman B A 1977 Management model for groundwater development. J. Water Resour. Planning Manage Div., Am. Soc. Civ. Eng. 103: 159-171

Willis R, Yeh W W G 1987 Groundwater systems planning and management (Englewood Cliffs, NJ: Prentice Hall)

Xiang Y, Sykes J F, Thomson N R 1995 Alternative formulations for optimal groundwater remediation design. J. Water Resour. Planning Manage. Div., Am. Soc. Civ. Eng. 121: $171-181$

Yakowitz S J 1982 Dynamic programming applications in water resources. Water Resour. Res. 18: 637-696

Yazicigil H 1990 Optimal planning and operation of multiaquifer system. J. Water Resour. Planning Manage. Div., Am. Soc. Civ. Eng. 116: 435-454

Yazicigil H, Rasheeduddin M 1987 Optimisation model for groundwater management in multi-aquifer systems. J. Water Resour. Planning Manage. Div., Am. Soc. Civ. Eng. 113: 257-273

Yeh W W G 1992 Systems analysis in groundwater planning and management. J. Water Resour. Planning Manage. Div., Am. Soc. Civ. Eng. 118: 224-237 